\title{
Web-Based Medical Information with Inventory System of LGU Jones Health Services Unit Jones, Isabela
}

\author{
Dr. Maria Visitacion Gumabay ${ }^{1}$, Christian B. Corpuz ${ }^{2}$ \\ ${ }^{1}$ Saint Paul University, Philippines, mvgumabay@ spup.edu.ph \\ ${ }^{2}$ Isabela State University, Philippines, Christian.corpuz@isu.edu.ph
}

\begin{abstract}
The study entitled " Web-based Medical Information with Inventory System of LGU Jones Health Services Unit, was designed and developed to create a web-based system that answers the existing problems encountered in the present procedures In terms of organizing and minimizing the use of paper in the clinic. The purpose is to design a system that collects and stores patients' information, medicine information, medicine inventory and that makes it available for decision making for analysis and for management action and policy making. The administrator must $\log$ in to the system in order to record and input all the information needed in the transaction. Using database, all inputted data are stored in it. All medicine information, and patient information are also stored in the database. Related studies and literature were also integrated in this study, observation, interview internet research and questionnaires were the design used. The Web-based Medical Information and Inventory System of LGU Jones Health Services Unit was developed using the Bootstrap, Jquery, MySql.
\end{abstract}

Key words: Web-Based Systems, Record Management, PHP, My SQL, Bootsrap, Jquery, DRRMC, Health Services Unit.

\section{INTRODUCTION}

Technology is important nowadays, because it makes life more convenient and people were able to make work easier and faster. And because of technology, man's work were be more reliable and produce accurate results. This study was conducted for the purpose of removing manual process that people manipulate and do things that are beneficial to them. Technology stands the one that has an important role in our modern way of life.. Printed medical information created by individual may be part of a paper-based Medical Information System that maybe difficult to locate, update and share with others. Paper- based information are subject to physical loss and damage during a natural disaster. And because of these problems, the researchers developed Webbased Medical Information with Inventory System of LGU
Jones Health Services Unit that minimize paper-works, provides recording of patient information including the findings on that particular patient, the time and date of visit, medical prescription and inventory of medicines. Reliable and fast preparation of reports needed, ease of access in terms of patients' information.

\subsection{Literature Review}

\subsubsection{Related Studies}

In the study of Vispo N. and Salvatuz R. (2017), develop a computerized patient's Medical Record System for San Jose Hospital and Trauma Center that would help the hospital in the processing and keeping of medical records of their clients. The proposed system was intended to operate in wireless LAN connection as suggested by the clients for they have already the resources needed for the application of the said system. Interactive Life Cycle Model was used to develop the system. Survey results showed that respondents who tried the system gave a positive feedback.

In the study of Balsita M. (2017), stated in his study that one of the first attempts in the conversion of patient dental records of UPCD to electronic records is Open Dentist. However, the system lacks some functionalities and problems were encountered when it comes to patient records access. Clinic and Dental Information System, the second version of Open Dentist, gives UPCD clinicians free access and storage of electronic patient dental records. The system stores patient dental records containing different forms derived from the UPCD admitting section form. Dentist also provides a graphical representation of the teeth in which observations are easily added with just a few clicks. Moreover, the second version is able to address the problem with the running time of a patient dental chart. New and improved functionalities such as querying for patients and statistics are available in Dentist. The system allows clinicians to easily search for patients according to specified criteria.

In the study of Valdez K. (2017), stated that Inventory management is a prime task for an organization to achieve 
its goals of maintaining appropriate level of inventory and minimizing waste. A web-based system of managing inventory in a university setting is expected to help various laboratories keep an update on the status of their tools and equipment. In this study, a model is presented for putting a web-based inventory system in place in five different laboratories of an Engineering Department in a large public university in Davao. In designing such a system, PHP has been employed as a development language and MySQL as a backend database with CSS implemented for the interface. Two screen-shots have been illustrated to offer a glimpse of the proposed web-based system and its applications. This online system would help the personnel in charge of the laboratories find out the capacity of the labs as well as the relevant information of asset availability, and replace the current practice of extensive manual recording of asset documentation thus holding a key for an organization like university to gaining competitive advantage through efficient operational performance..

In the study of M, Suriya \& K, Meenakshi \& P, Sneha \& B, Venkata. (2020) titled Intelligent Medical Information System. Now a days, meeting doctors is quite too frequent. People always meet doctors in order to get treatment for their symptoms. Existing clinic registration systems have to make an appointment with a doctor only when they visit the clinic or hospital and wait in queues for long hours in order to get treatment and everything was tedious too because everything was done manually. So many mistakes could have been made. Therefore, many online appointment systems have been developed in order to book appointments with doctors through mobile application. No priority based appointments and an emergency situation for appointments with doctors is considered. All these aspects are taken into consideration and an online appointment booking system with doctors is especially designed for the Madurai city, Tamil Nadu, India. We will design an android application that tracks the location of a user using particle swarm optimization algorithm and also it displays the details of all the hospitals and clinics in the Madurai district and the available specialists in each stream. This system uses java programming language as interface between the user and doctor and MySQL as the database.

In the study of Moss, Jeffrey \& Schwenk, Hayden \& Chen, Michael \& Gaskari, Shabnam. (2021). titled "Drug Shortage and Critical Medication Inventory Management at a Children's Hospital During the COVID-19 Pandemic. Drug shortages have significantly affected the ability to provide care at pediatric institutions, particularly in the inpatient and critical care settings. The coronavirus disease 2019 (COVID-19) pandemic highlighted additional challenges with drug supply chains. A working group consisting of pharmacy management, clinical pharmacists, and pharmacy buyers met regularly at the beginning of the COVID-19 pandemic. In collaboration with medical staff leadership and the Pharmacy and Therapeutics Committee, we developed a pediatric critical drug list to track essential medications for targeted monitoring. We created an inventory model with easily modifiable input variables related to patient and hospital data. This model was aligned across affiliate health care systems to increase transparency of our hospital's surge capacity for managing patients with COVID-19. Here, we share our framework for modeling drug inventory management at a freestanding children's hospital during a global pandemic..

In the study of Muluk, Asmuliardi \& Jonrinaldi, Jonrinaldi \& Asri, Fadhita. (2020) titled "A proposed policy of medication inventory system in pharmacy installation." Hospital must be aware with the management in pharmacy especially on pharmacy inventory management in pharmacy installation. Semen Padang Hospital is a facilities that provides health service that has one pharmacy as the central place that is responsible for the procurement, storage and distribution of medication throughout the hospital. But in current conditions, Semen Padang Hospital could not fulfill the demand of the medicine for its patients because there is out of stocks for several medicines at the inventory and its affect to the period of getting those required medicines for the patients where most of them have a pending issue. The number of pending receipt of medicines significantly increase month-by-month and its increasing ten times greater from July until December. This condition happened because there is no policy to manage the procurement of medication in Semen Padang Hospital. First the medicines will be classified into three classes by using $\mathrm{ABC}$ analysis based on its value of investment. The proposed medication inventory policy for class A and vital medicines are solved using probabilistic inventory model (EOQ+Safety stock) and for class B and C (Non - vital) solved using Joint Replenishment. This models are used because of the assumptions are suitable with the actual condition in Semen Padang Hospital. By using proposed inventory policy, Semen Padang Hospital has saving money potential as much $63.27 \%$ of the cost spend based on the current policy that applied right now in the last three months in 2018 (October - December 2018).

\subsubsection{Disaster Risk Reduction Management Studies}

In the study of Tardieu, Philippe. (2015) titled "Introduction to a Dental and Medical Inventory, Order and Traceability Management Software.” All clinics are facing the same issues related to items orders, traceability, inventory, real time evaluation of the inventory, expire dates management, price of same items sold by different distributors, medico-legal constraints, consumption evaluation of all Items or of some dedicated items, export of payment details to accountancy, etc. 


\subsection{Conceptual Framework}

The paradigm bellow shows how the researcher gathered and process data needed to provide outcomes.

\begin{tabular}{|c|c|c|}
\hline INPUT & PROCESS & OUIPUT \\
\hline $\begin{array}{l}\text { a. Interviewand } \\
\text { Observation } \\
\text { Result } \\
\text { b. Theoriesfrom } \\
\text { Literature } \\
\text { Reviews } \\
\text { c. Suggestionsof } \\
\text { ITExpertsand } \\
\text { Stakeholders }\end{array}$ & $\begin{array}{l}\text { a. Problem } \\
\text { Recognition } \\
\text { b. System } \\
\text { Development } \\
\text { c. Assessmentof } \\
\text { theSystem } \\
\text { Developed }\end{array}$ & $\begin{array}{l}\text { a. Web-Based } \\
\text { M edical } \\
\text { Information } \\
\text { with } \\
\text { Inventory } \\
\text { System } \\
\text { b. Effectiveand } \\
\text { Efficient Record } \\
\text { Management } \\
\text { System }\end{array}$ \\
\hline 4 & FEEDBACK & \\
\hline
\end{tabular}

Figure 1. Conceptual Framework

\subsection{Statement of the Problem}

The study entitled "Web-based Medical Information with Inventory System of LGU Jones Health Services Unit" sought to develop a Web-Based System that would improve the processes and fast tract delivery of services of Jones Health Services Unit. In order to make this possible, the researcher seeks to answer the following specific questions.

a. What are the problems experienced by the LGU Jones Health Services Unit in managing records of patients and inventory of medicines?

b. What are the technologies that could be maximized to help solved current challenges being encountered by the LGU Jones Health Services Unit?

c. What are the resources, processes, outputs and features that needs to be included for the development of "Web-Based Medical Information with Inventory System"?

d. What is the extent of effectiveness/efficiency of the developed Web-Based Medical Information with Inventory System as perceived by stakeholders?

\subsection{Significance of the Study}

This study rests its significance on the following:

LGU Jones Health Services Unit. The output of this study could contribute a lot in managing patients record and medicines.

Head of the LGU Jones Health Services Unit. The system will give clear view on the resources being utilize and the record of patients. She can easily tract, update and supervise the patients record and the inventory of their medicines.

System Developers. System developers can make used of this research as basis of features that could be included in related systems they are developing.

Researcher. This research gives the researcher valuable knowledge and experience in the field of research. This is also a way to help the LGU Jones Health Services Unit boost their capability to serve their constituents.

Future Researchers. This research is can be used as basis for future researchers in terms of Web-Based systems development.

\subsection{Scope and Limitations}

This study only focus its data gathering to LGU Jones Health Services Unit for the development of desired outcomes. Since the output is custom tailored base on the needs of Jones Health Services Unit, it might not be applicable in other Local Government Units.

\subsection{Definition of Terms}

The following terms are hereby defined for better understanding on how it was used in this study:

Agile Methodology. The Agile Method is a particular approach to project management utilized in software development. This method assists teams in responding to the unpredictability of constructing software. It uses incremental, iterative work sequences commonly known as sprints.

Web-Based. Applications are a particular type of software that allows users to interact with a remote server through a web browser interface.

Medical Information. Any individually identifiable information, in electronic or physical form, in possession of or derived from a provider of health care.

Inventory. a complete list of items such as property, goods in stock

Patient. a person receiving or registered to receive medical treatment.

Medicine. the science or practice of the diagnosis, treatment, and prevention of disease.

$L G U$. Local Government Unit.

$H S U$. Health Services Unit 


\section{METHODOLOGY}

\subsection{Research Design}

The researcher used descriptive research to identify the needs of the LGU Jones HSU in terms of Recording and managing inventory of medicines. As a guide, the researcher made used of Agile SDLC model as shown below.

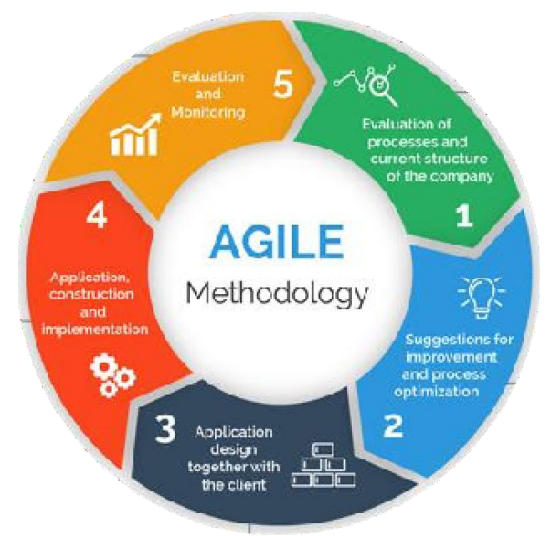

Figure 2. Agile SDLC model (https://site.gitscrum.com/what-isagile-methodology)

The following are the activities done in each phase:

Phase 1. The researcher mapped processes to determine the starting point and the "Actual State".

Phase 2. Optimized the processes using the right combination of technologies.

Phase 3. The researcher and the Head of HSU have chosen technologies and reviewed options. The respondents have been part of the project from the very beginning and their feedback was vital in the system development.

Phase 4. Delivery of developments to the Head of HSU to operate and request for changes as a need arises. In this way, acceptability of system units was assured.

Phase 5. This part determines key points and reports, in order to monitor that the process is working as agreed.

\subsection{Respondents of the Study}

The main respondents of the study were the Head and Nurse of LGU Jones HSU of Jones, Isabela.

\subsection{Instrumentation}

2.3.1 Interview Guide/Observation/Field Notes The researcher used interview guide during the actual interview of the respondents does obtaining detailed procedures of the manual flow of recording patent information and management of medicine inventory. The procedures provided the researcher knowledge and understanding on problems encountered, strengths and weak points of the manual recording of patient information and management of medicines.

\subsubsection{Literature Review}

The researcher used Library Research to gather information in various materials such as books, research manuscripts and journals, which provided the researcher ideas, related literature and studies that are helpful in the development of the system. The researchers also browsed through internet sites for related literature and studies.

\subsubsection{Questionnaire}

Feedback from the respondents were gathered through a questionnaire in order to examine the user and client's satisfaction of the new system.

\subsection{Data Gathering Procedures}

A letter request about the proposal along with the concept paper was submitted and approved by the Head of HSU. A letter of consent is also included in the questionnaires used during the effectiveness evaluation of the system. The researcher successfully used the above-mentioned instruments in gathering vital information to support answers of the specific objectives. During the testing process, IT experts and stakeholders gave their suggestions and the researcher incorporated those valuable suggestions in the system.

\subsection{Data Analysis}

\subsubsection{CONTENT ANALYSIS}

This was done through reading contents of gathered data, field notes and web sites related to the study.

\subsubsection{NARRATIVE ANALYSIS}

Important key points during interview were considered during the program process formulation and valuable suggestions was noted during system evaluation and incorporated in the system. 


\subsubsection{MATRIX}

Matrix was used to compare features of the system developed and implemented by the researcher

\subsubsection{MEAN AND GRAND MEAN}

The researcher used the mean and grand mean in analyzing and interpreting the result of the gathered data through questionnaire. The table below show the scale, range and qualitative description as basis of interpreting the result of the data.

Qualitative Rating, Scale and Range

\begin{tabular}{|c|c|c|}
\hline Scale & Range & $\begin{array}{l}\text { Qualitative } \\
\text { Description }\end{array}$ \\
\hline 5 & $4.50-5.49$ & Excellent \\
\hline 4 & $3.50-4.49$ & Very good \\
\hline 3 & $2.50-3.49$ & Good \\
\hline 2 & $1.50-2.49$ & Poor \\
\hline 1 & $0.50-1.49$ & Needs Improvement \\
\hline
\end{tabular}

Table 2. Qualitative Rating Scale

\section{RESULTS AND DISCUSSION}

\subsection{Problem Recognition}

After analysis of data collected, the researcher found the following problems encountered on the old patient record management, inventory and illustrated further using the fishbone diagram below.

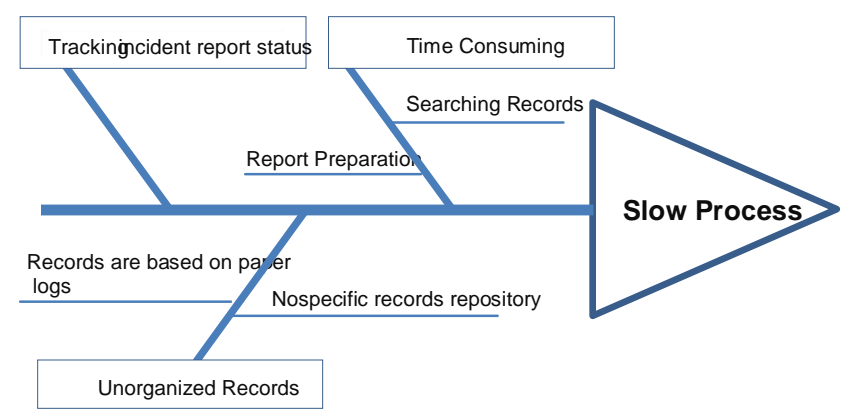

3.2 Flow Chart of monthly, quarterly and yearly reports

preparation

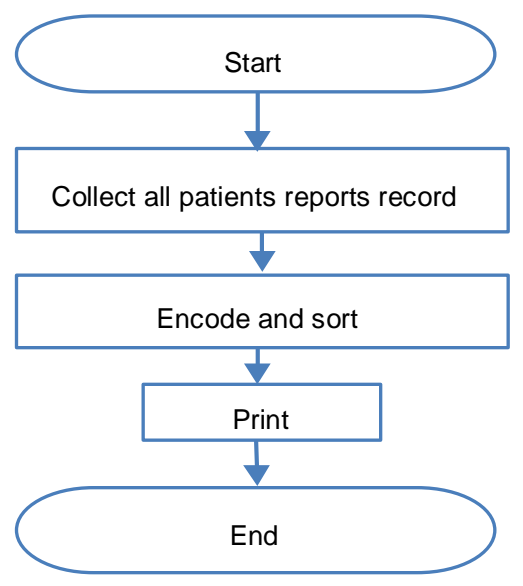

Figure 4. Old Flow Chart of Report Preparation

3.3 Flow Chart of Old Inventory Management of Medicines

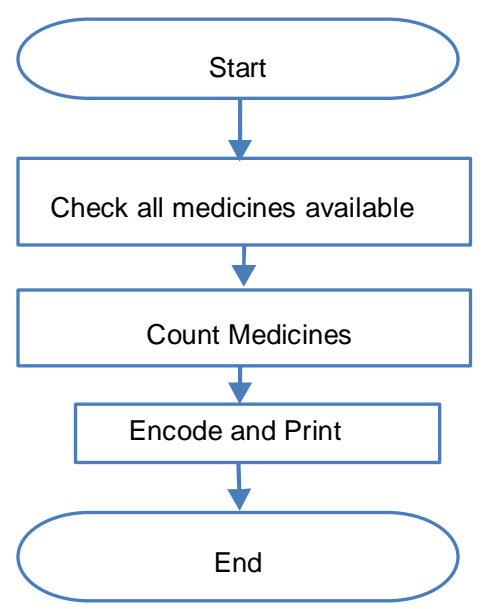

Figure 4. Old Flow Chart of Inventory Management of Medicines

Figure 3. Fishbone Diagram 


\subsection{Functional Decomposition Diagram}

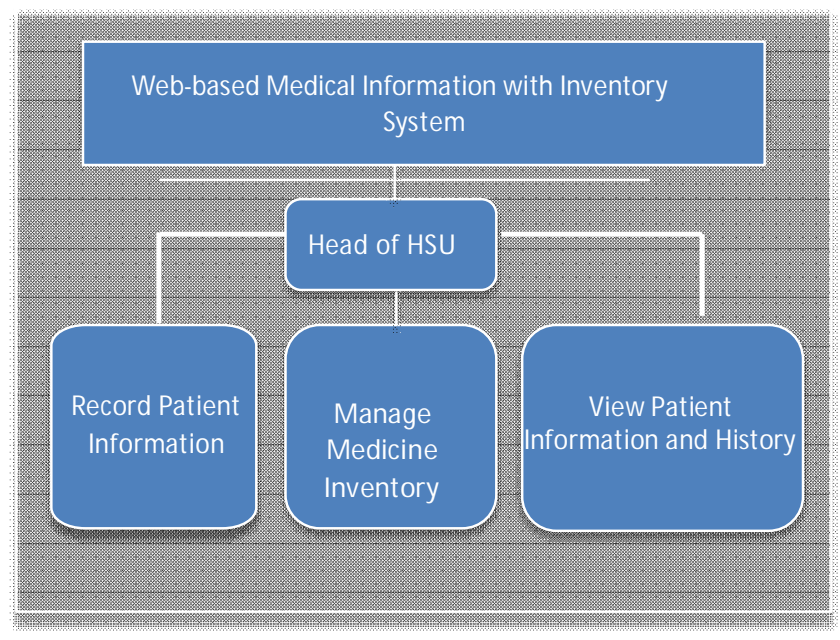

\section{Figure 5. Decomposition Diagram}

In this diagram, the researcher shows the breakdown structure of the developed system into smallest component. The used of the system highly depends on the HSU personnel.

3.5 Technical Feasibility

\begin{tabular}{|c|c|c|}
\hline $\begin{array}{l}\text { Present } \\
\text { System }\end{array}$ & Proposed System & Variance \\
\hline \multicolumn{3}{|l|}{ Hardware } \\
\hline 1 Computer & 2 Computer Set & 1 Computer Set \\
\hline & 1pc Modem & 1pc Modem \\
\hline
\end{tabular}

\section{Table 3. Requirements Specification}

Table 3 shows the hardware inventory of the old system and the list of devices needed to run the developed system. It was used as basis when the Head of HSU request for the purchase of lacking devices.

\subsection{Testing}

Series of tests was done to check error and validate if the system provides the desired output. The testing was conducted during and after the development of the system.

\subsubsection{Compatibility Testing}

To ensure that the system runs to the existing hardware, this test was used to test the compatibility of the different components of the system. After the test, it came out that the existing hardware was compatible to run all the features of the developed system.

\subsubsection{Performance Testing}

This type of test was used to determine if the systems performance is acceptable to the Head of HSU. It came out that the performance of the system is generally acceptable to Head of HSU and other stakeholders.

\subsubsection{Unit Testing}

This test was done to ensure that the source code is free of data, logic or standard errors. This was done by compiling the source code and the researcher checked for errors.

\subsection{Results of Effectiveness Evaluation}

The following data summarizes the results of System Effectiveness of the system as perceived by thirty one (31) respondents of the study.

\begin{tabular}{|c|c|c|}
\hline Key Rating Area & $\begin{array}{l}\text { Using the } \\
\text { Old } \\
\text { Incident } \\
\text { Report } \\
\text { Managemen } \\
\text { t }\end{array}$ & $\begin{array}{c}\text { Using the } \\
\text { Web-based } \\
\text { Medical } \\
\text { Information } \\
\text { with } \\
\text { Inventory } \\
\text { System }\end{array}$ \\
\hline $\begin{array}{l}\text { 1. It's easy to record } \\
\text { patient info. }\end{array}$ & 3 & 5 \\
\hline $\begin{array}{l}\text { 2. Head of HSU easily } \\
\text { view and manage } \\
\text { medicine inventory. }\end{array}$ & 3.5 & 5 \\
\hline $\begin{array}{l}\text { 3. Tracking of } \\
\text { medicine's expiration } \\
\text { date is easy. }\end{array}$ & 2.2 & 4.5 \\
\hline $\begin{array}{l}\text { 4. ease of access in } \\
\text { terms of searching } \\
\text { and tracking patient } \\
\text { info. }\end{array}$ & 2 & 4.5 \\
\hline $\begin{array}{l}\text { 5. Report preparation } \\
\text { is done easily. }\end{array}$ & 3 & 5 \\
\hline Grand Mean: & 2.98 & 4.8 \\
\hline
\end{tabular}

Table 4. Average Rating of the old and new system as perceived by the respondents

Table 4 shows that the respondents perceived the old incident report management system to have performance rate of 2.98 - Good. While the same respondents perceived the Web-based Medical Information with Inventory System to have performance rate of 4.8-Excellent. 
3.8 The developed systems and sample GUI's of the System

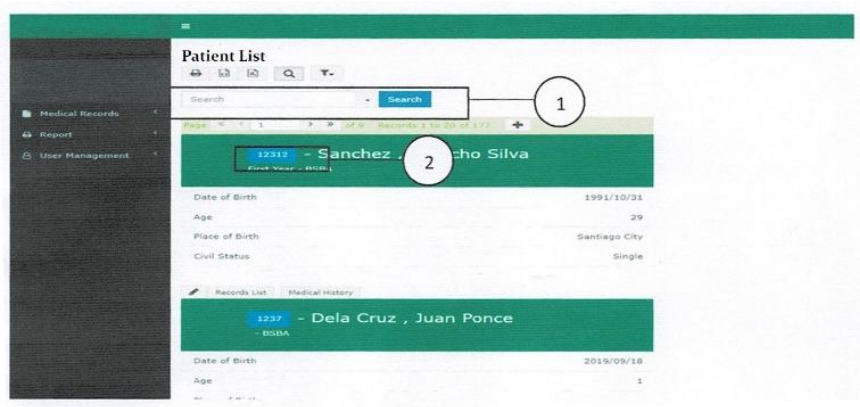

Figure 6. Patient Module of Web-based Medical Information with Inventory System

The Patient module consist of recording patient information, viewing patient list.

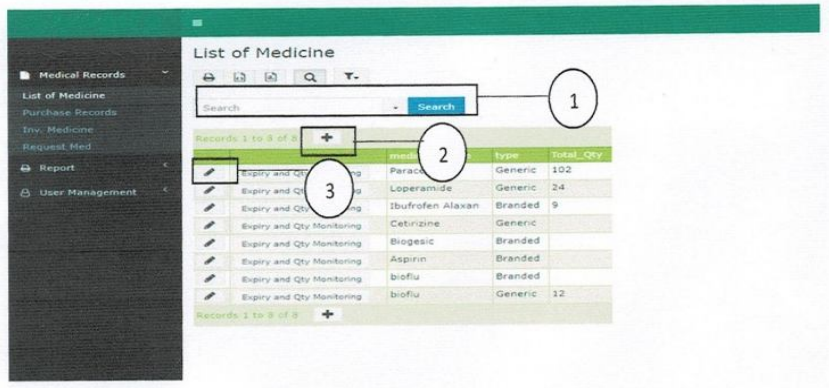

Figure 7. Medicine Module

This module is used to manage medicine resources. Searching for medicine, quantity of medicine available, expiration date, type of medicine. The user can add and modify this information.

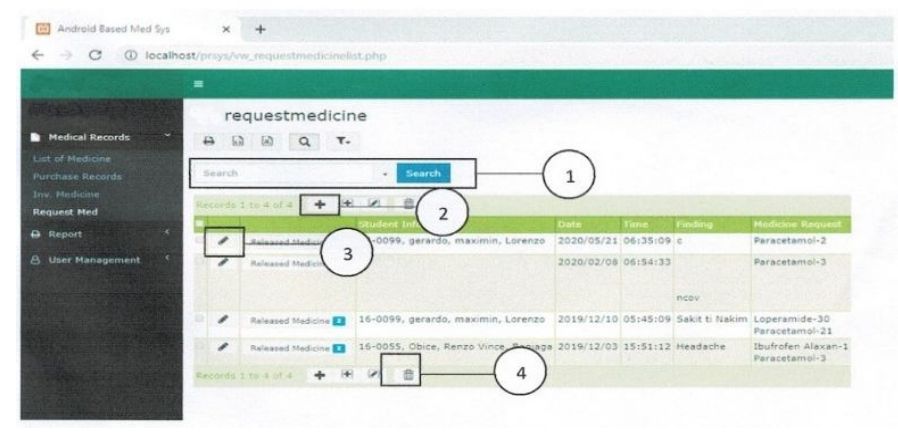

Figure 8. Request Medicine

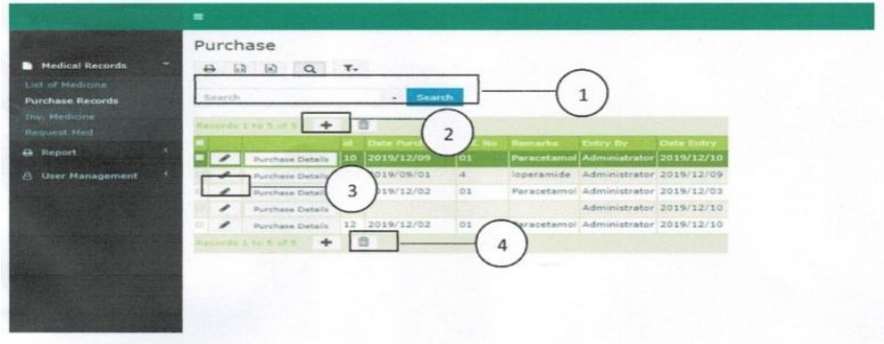

Figure 9. Purchase Records
This part of the system is used to request medicine if there are no available medicine specially if it is badly needed by the patient.

This module shows the purchase request of medicines.

\section{CONCLUSION}

In the light of the findings of the study, the researcher concludes that there were problems encountered in the old system and eliminated after the Web-based Medical Information with Inventory System was implemented. The respondents perceived the new system to be more effective than the old system. The recommendations by IT Experts and Stakeholders was very useful and adds clarity in the main display of the Web-based Medical Information with Inventory System.

\section{ACKNOWLEDGMENT}

This work was supported by Health Services Unit, Local Government Unit of Jones, Isabela and the St. Paul University Philippines, Tuguegarao City. The researchers also acknowledged the unending support of Isabela State University and the Commission on Higher Education.

\section{REFERENCES}

1. AbinboJa S, and Jilantikiri L. (2017). "Development of an Automated Healthcare Record Management System", University of Ilorin's Health Care, Vol.4, Page 79.

2. Ang kwee kwan (2017). "Clinic Management System", Faculty of information and comtnunication Technology (Perak Campus), UTAR. Vol. 7, Page 34.

3. Alegre B, and I-xtndicho A. (2016)."Commercially viable electronic health records system with versatile image capturing application for ENT Clinic", De txt Salle University, Manila, Philippines, Vol. 3, Page 51.

4. Baratang A. (2() Clinic medicine Information Ylanagement System Monticello Street, New York, NY 12701, vol. l. Page 42.

5. Moss, Jeffrey \& Schwenk, Hayden \& Chen, Michael \& Gaskari, Shabnam. (2021). Drug Shortage and Critical Medication Inventory Management at a Children's Hospital During the COVID-19 Pandemic. The Journal of Pediatric 
Pharmacology and Therapeutics. 26. 21-25. $10.5863 / 1551-6776-26.1 .21$.

6. Muluk, Asmuliardi \& Jonrinaldi, Jonrinaldi \& Asri, Fadhita. (2020). A proposed policy of medication inventory system in pharmacy installation (case study in Semen Padang Hospital). AIP Conference Proceedings. 2217. 030179. 10.1063/5.0000714.

7. M, Suriya \& K, Meenakshi \& P, Sneha \& B, Venkata. (2020). Intelligent Medical Information System. INTERNATIONAL JOURNAL OF ADVANCED INFORMATION AND COMMUNICATION TECHNOLOGY. 56-63. 10.46532/ijaict-2020014

8. Balsita M. (2017). "Clinic and Dental Information System", University of the Philippines Manila College of Arts and Sciences Department of Physical Sciences and Mathematics, Vol. 2, Page 19.https://www.pcmag.com /encyclopedia /term /55407 /cellular-modem [16] Related Literature and Studies Search Engine:

https://scholar.google.com.ph 